DOI: $10.1590 / 1809-6891 v 15 \mathrm{i} 228081$

\title{
EFEITO HETERÓTICO NAS PARTES NÃO-INTEGRANTES A CARCAÇA DE NOVILHOS TERMINADOS EM CONFINAMENTO
}

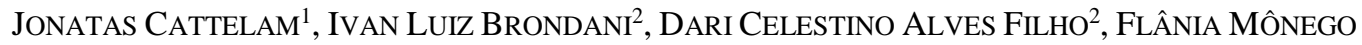

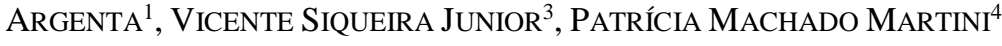 \\ ${ }^{1}$ Pós Graduandos da Universidade Federal de Santa Maria, Santa Maria, RS, Brasil - \\ jonatascattelam@yahoo.com.br \\ ${ }^{2}$ Professores Doutores da Universidade Federal de Santa Maria, Santa Maria, RS, Brasil. \\ ${ }^{3}$ Zootecnista Pós Graduando da Universidade Federal de Santa Maria, Santa Maria, RS, Brasil. \\ ${ }^{4}$ Graduanda em Zootecnia, bolsista de Iniciação Científica da Universidade Federal de Santa Maria, Santa Maria, \\ RS, Brasil.
}

\section{RESUMO}

Objetivou-se avaliar o efeito heterótico sobre as partes não-integrantes da carcaça de novilhos do cruzamento entre as raças Charolês (Ch) e Nelore $(\mathrm{Ne})$ e cruzados entre essas raças de quinta $(21 / 32 \mathrm{Ch} 11 / 32 \mathrm{Ne} ; 21 / 32 \mathrm{Ne}$ $11 / 32 \mathrm{Ch})$ e sexta $(43 / 64 \mathrm{Ch} 21 / 64 \mathrm{Ne} ; 43 / 64 \mathrm{Ne} 21 / 64 \mathrm{Ch})$ gerações, terminados em confinamento. $\mathrm{O}$ efeito heterótico foi positivo para pesos de abate e corpo vazio em todas as gerações, cabeça na quinta $(1,29 \mathrm{~kg})$ e sexta $(1,04 \mathrm{~kg})$ gerações e orelhas na quinta geração $(0,17 \mathrm{~kg})$. Houve efeito heterótico em ambas as gerações para rúmen-retículo e intestinos e abomaso na quinta geração. Em peso absoluto, houve efeito heterótico para coração, pulmões, rins e baço $(0,14 ; 0,11 ; 0,55$ e $0,16 \mathrm{~kg}$, respectivamente) na quinta geração e para pulmões $(0,61$ $\mathrm{kg}$ ) na sexta geração. O efeito heterótico foi positivo para gorduras renal, do coração e do trato digestório em ambas as gerações e gordura inguinal na sexta geração. Em relação ao peso de corpo vazio, houve efeito heterótico para couro, em ambas as gerações, orelhas na quinta geração e gordura de coração e sangue, na sexta geração. Novilhos cruzados apresentam maiores pesos dos diferentes conjuntos dos componentes externos à carcaça em relação a animais definidos das raças Charolês e Nelore.

PALAVRAS-CHAVE: couro, cruzamento, fígado, peso de corpo vazio, trato digestório.

\section{HETEROTIC EFFECT ON NON-INTEGRANT PARTS OF CARCASS FROM STEERS FINISHED IN FEEDLOT}

\section{ABSTRACT}

The objective of this study was to evaluate the heterotic effect on non-integrant parts of carcass from steers of the breeds Charolais (Ch) and Nellore (Ne) and crossbreeds from fifth $(21 / 32 \mathrm{Ch} 11 / 32 \mathrm{Ne} ; 21 / 32 \mathrm{Ne} 11 / 32 \mathrm{Ch})$ and sixth (43/64Ch $21 / 64 \mathrm{Ne}$; 43/64Ne $21 / 64 \mathrm{Ch})$ generation, finished in feedlot. The heterotic effect was positive for slaughter weight, empty body weight in both generations, head in fifth $(1.29 \mathrm{~kg})$ and sixth $(1.04 \mathrm{~kg})$ generation and ears in fifth generation $(0.17 \mathrm{~kg})$. There was a heterotic effect on fifth and sixth generation for rumen-reticule and intestines, respectively, and abomasum on fifth generation. In absolute weight, a heterotic effect was observed on fifth generation for heart, lungs, kidneys and spleen $(0.14 ; 0.11 ; 0.55$ and $0.16 \mathrm{~kg}$, respectively) and lungs in sixth generation $(0.61 \mathrm{~kg})$. The heterotic effect was positive for fats of heart, kidney and digestive tract in both generations and for inguinal fat in sixth generation. In relation to empty body weight, there were heterotic 
effects for rawhide, in both generations, ears in fifth generation, and heart fat and blood in sixth generation. The crossbred steers showed higher weights for different external compounds in relation to purebred Charolais or Nellore.

KEYWORDS: crossbreeds, digestive tract, empty body weight, liver, rawhide.

\section{INTRODUÇÃO}

$\mathrm{Na}$ comercialização de bovinos dá-se ênfase a características relacionadas à carcaça e à carne dos animais, porém, de acordo com Kuss et al. ${ }^{1}$, as indústrias frigoríficas preocupam-se em quantificar os componentes não-integrantes da carcaça, no intuito de elevar a lucratividade com o abate dos animais. Conforme Missio et al. ${ }^{2}$, embora não existam estudos que comprovem a lucratividade real dos sistemas frigoríficos, parte das despesas operacionais é custeada com dividendos provenientes da comercialização de órgãos, couro, carne da cabeça e demais resíduos destinados à ração animal.

Embora o produtor não seja remunerado pelos componentes não-integrantes da carcaça, esses são relevantes pois estão relacionados aos rendimentos de carcaça e às exigências nutricionais ${ }^{3}$. Segundo Melo et al. $^{4}$, diferentes capacidades de ingestão são observadas nos distintos grupos genéticos, sendo que os diferentes aportes de nutrientes podem influenciar o desenvolvimento dos órgãos e trato gastrintestinal. De acordo com Cattelam et al. ${ }^{5}$, o peso do trato digestório é maior em animais com predomínio taurino em relação aos mestiços zebuínos, assim como Jorge \& Fontes ${ }^{6}$ relataram maior peso dos órgãos internos em bovinos de raças taurinas ou mestiços de raças leiteira em comparação aos zebuínos.

De acordo com Pacheco et al. ${ }^{7}$, a avaliação das partes não-integrantes da carcaça deve ser utilizada como informação auxiliar para compreender características relacionadas ao desempenho e à carcaça. Kuss et al. ${ }^{8}$ afirmaram que diferenças no consumo alimentar e nos rendimentos de carcaça entre bovinos Bos taurus taurus e Bos taurus indicus podem estar associadas a características dos tecidos de revestimento e membros. Menezes et al. ${ }^{9}$ estudaram a heterose sobre os componentes nãointegrantes da carcaça de novilhos das raças Charolês e Nelore e verificaram que a heterose retida, para pesos ajustados ao peso de corpo vazio, foi positiva para o rendimento de carcaça e negativa para o conjunto do trato digestório, ao passo que Menezes et al. ${ }^{10}$ observaram heteroses negativas para o total dos componentes externos à carcaça, ressaltando que para as gorduras são desejáveis heterose negativas.

Jorge et al. ${ }^{11}$ relataram que é conveniente estudar os componentes da não-carcaça devido às suas variações conforme o grupo genético e por sua relação com as exigências de mantença e ganho de peso. Desse modo, objetivou-se com este estudo avaliar o efeito heterótico sobre as partes não-integrantes da carcaça de novilhos de diferentes gerações do cruzamento entre as raças Charolês e Nelore, terminados em confinamento.

\section{MATERIAL E MÉTODOS}

O presente estudo foi realizado no Laboratório de Bovinocultura de Corte, pertencente ao Departamento de Zootecnia da Universidade Federal de Santa Maria, localizado no município de Santa Maria, na região fisiográfica da Depressão Central do estado do Rio Grande do Sul ${ }^{12}$. Foram utilizados 48 novilhos, com idade inicial de 20 meses, os quais eram definidos das raças Charolês (Ch), com 214,9 \pm $11,9 \mathrm{~kg}$, e Nelore $(\mathrm{Ne})$, com 209,0 $\pm 17,9 \mathrm{~kg}$; cruzados entre essas raças de quinta geração: $21 / 32 \mathrm{Ch} 11 / 32 \mathrm{Ne}(259,9 \pm 10,8 \mathrm{~kg})$ ou $21 / 32 \mathrm{Ne}$ $11 / 32 \mathrm{Ch}(256,0 \pm 10,3 \mathrm{~kg})$; e de sexta geração: $43 / 64 \mathrm{Ch} 21 / 64 \mathrm{Ne}(235,4 \pm 13,6 \mathrm{~kg})$ ou $43 / 64 \mathrm{Ne}$ $21 / 64 \mathrm{Ch}(266,8 \pm 16,0 \mathrm{~kg})$.

Os animais foram confinados em baias coletivas, sendo essas parcialmente cobertas, providas de piso de alvenaria e comedouro de concreto com disponibilidade de $0,80 \mathrm{~m}$ por animal e bebedouro regulado por torneira-boia. Os novilhos permaneceram confinados até atingir condição adequada para o abate, o qual foi determinado pelo critério de condição corporal, preconizando adequada deposição de gordura de cobertura da carcaça, avaliada por meio do escore corporal dos animais, seguindo metodologia descrita por Lowan ${ }^{13}$, em que escore corporal $=1-$ muito magro; escore corporal $=5$ - muito gordo. A dieta, com $11,5 \%$ de proteína bruta e $62 \%$ de 
nutrientes digestíveis totais, continha relação volumoso:concentrado de 39:61 (base na matéria seca), sendo o volumoso utilizado a silagem de sorgo (Sorghum bicolor L Moench). Os animais foram alimentados à vontade duas vezes ao dia, sendo metade da alimentação ofertada às $08: 30 \mathrm{~h} \mathrm{e}$ o restante às $14: 00 \mathrm{~h}$. Os animais foram pesados no início do período experimental e em intervalos de 21 dias, até o embarque para o frigorífico, sendo previamente submetidos a jejum de sólidos e líquidos por 14 horas.

Após atingir grau de acabamento adequado para comercialização, ao menos $3 \mathrm{~mm}$ de espessura de gordura, os novilhos foram submetidos a jejum de sólidos e líquidos de 14 horas, a fim de mensurar o peso de abate, sendo, em seguida, transportados para frigorífico comercial, localizado a $30 \mathrm{~km}$ da fazenda experimental, e abatidos seguindo o fluxo do estabelecimento. Durante o abate, todas as partes do corpo do animal foram separadas e pesadas individualmente e consistiram de conjunto de componentes externos: cabeça, patas, orelhas, chifres (quando presentes), vassoura da cauda e couro; conjunto de órgãos vitais: pulmão, fígado, rins, coração e baço; conjunto de gorduras ginternas: gordura de toalete, gordura inguinal, gordura renal, gordura do coração, gordura ruminal, gordura do abomaso e gordura intestinal; conjunto do trato digestivo vazio: rúmen + retículo, omaso, abomaso, intestinos (grosso + delgado); e sangue. A gordura do trato digestório refere-se à soma das gorduras ruminal, do abomaso e dos intestinos. Antes de serem encaminhadas à câmara de resfriamento, as duas meia-carcaças foram identificadas e pesadas, obtendo-se o peso de carcaça quente, e pesadas novamente após 24 horas de resfriamento para se obter o peso de carcaça fria. O peso de corpo vazio foi obtido pelo somatório do peso de carcaça quente, sangue e de todos os conjuntos dos componentes agrupados conforme citado anteriormente.

O delineamento experimental foi o inteiramente casualizado, sendo cada novilho uma unidade experimental. Os dados foram submetidos à análise de variância pelo proc GLM, usando-se o seguinte o modelo matemático:

$$
Y_{i j}=\mu+G R_{i}+G_{j}(G E R)_{i}+\varepsilon_{i j}
$$

em que: $Y_{i j}$ representa as variáveis dependentes; $\mu$ a média geral das observações; GER é a geração do cruzamento entre as raças Charolês $(\mathrm{Ch})$ e Nelore $(\mathrm{Ne})$, sendo 1 (definidos);
5 (cruzados de quinta geração) e 6 (cruzados da sexta geração); GG representa o grupo genético do novilho, sendo 1 (Charolês) e 2 (Nelore) dentro da GER $1 ; 1$ (21/32Ch $11 / 32 \mathrm{Ne})$ e $2(21 / 32 \mathrm{Ne}$ 11/32Ch) dentro da GER 5; 1 (43/64Ch $21 / 64 \mathrm{Ne})$ e $2(43 / 64 \mathrm{Ne} 21 / 64 \mathrm{Ch})$ dentro da GER $6 ; \varepsilon_{\mathrm{ij}}$ o erro residual aleatório. $\mathrm{O}$ efeito heterótico foi estimado por meio da análise de contrastes, sendo o efeito heterótico da G5 o contraste entre os cruzados da G5 em relação aos definidos e o efeito heterótico da G6 o contraste entre os mestiços da G6 em relação aos definidos. As diferenças entre cruzados e definidos foi realizada por meio do contraste entre os cruzados de ambas as gerações em relação ao Charolês ou em relação ao Nelore.

As médias foram classificadas pelo teste "F" e os parâmetros com efeito significativo comparados pelo "teste t", com $\alpha=0,05$. As varáveis foram testadas quanto à normalidade pelo teste Shapiro-Wilk, sendo realizadas as seguintes transformações: 1/ X (peso de abate, $\mathrm{kg}$; gordura inguinal, $\mathrm{kg}$; e coração, \% PCV); $\log \mathrm{X}$ (vassoura da cola, kg; e vassoura da cola, \% PCV); $\mathrm{X}^{* * 4}$ (gordura de coração, kg; gordura de coração, \% $\mathrm{PCV}$ ); $\operatorname{arsin} \mathrm{X}$ (orelha, $\mathrm{kg}$ ). As variáveis dependentes foram submetidas à análise de correlação de Pearson pelo procedimento proc CORR. As análises foram realizadas através do pacote estatístico SAS (Statistical Analysis System, versão 9.2).

\section{RESULTADOS E DISCUSSÃO}

Observa-se na Tabela 1 que o efeito heterótico foi significativo para o peso de corpo vazio na quinta e sexta gerações do cruzamento entre as raças Charolês e Nelore, com valores de 36,0 e $31,9 \mathrm{Kg}$, respectivamente, em concordância com o observado no efeito heterótico para o peso de abate. Essa elevação do peso de abate para os novilhos mestiços deve estar atrelado à participação da raça Charolês no cruzamento, visto que entre os animais definidos os novilhos taurinos apresentaram peso de abate superior aos animais da raça Nelore $(379,0$ e $328,7 \mathrm{~kg})$. De acordo com Menezes et al. ${ }^{14}$, animais da raça Charolês apresentam elevado valor genético aditivo para taxa de crescimento e peso adulto, sendo indicada para o uso em cruzamento quando se preconiza a busca por maiores pesos de abate. A correlação entre os pesos de abate e de corpo vazio foi de 0,99 ( $\mathrm{P}<0,0001)$ (Tabela 7), próxima ao resultado observado por Cattelam et al. ${ }^{15}$, que 
verificaram $r=0,98$, também com $\mathrm{P}<0,0001$. Para a relação entre o peso de abate e peso de corpo vazio, não foi observado efeito heterótico em nenhuma das gerações avaliadas. Semelhança no rendimento de corpo vazio para fêmeas de descarte de segunda e terceira gerações do cruzamento entre as raças Charolês e Nelore foi observada por Kuss et al. ${ }^{8}$, com rendimento médio de $81,51 \%$, inferior ao do presente estudo.

Tabela 1 - Efeito heterótico e diferença entre novilhos cruzados e definidos para pesos de abate, de corpo vazio, relação entre pesos de corpo vazio e de abate e rendimentos de carcaças quente e fria em relação ao peso de corpo vazio de novilhos de diferentes genótipos e gerações do cruzamento entre as raças Charolês e Nelore

\begin{tabular}{|c|c|c|c|c|c|}
\hline \multirow[t]{2}{*}{ Grupo Genético } & \multicolumn{5}{|c|}{ Característica } \\
\hline & Peso de abate, $\mathrm{kg}$ & $\begin{array}{l}\text { Peso de corpo } \\
\text { vazio, } \mathrm{kg}\end{array}$ & $\begin{array}{c}\text { Peso de corpo } \\
\text { vazio/ Peso de } \\
\text { abate, } \%\end{array}$ & $\begin{array}{c}\text { Rendimento } \\
\text { carcaça quente, } \\
\% \text { Peso de corpo } \\
\text { vazio } \\
\end{array}$ & $\begin{array}{l}\text { Rendimento de } \\
\text { carcaça fria, } \\
\% \text { Peso de corpo } \\
\text { vazio }\end{array}$ \\
\hline Charolês & $379,0 \pm 13,2 \mathrm{a}$ & $342,4 \pm 11,5$ & $90,3 \pm 0,45$ & $64,5 \pm 0,39$ & $62,8 \pm 0,39$ \\
\hline Nelore & $328,7 \pm 19,8 b$ & $293,9 \pm 17,3$ & $89,4 \pm 0,68$ & $65,2 \pm 0,58$ & $63,4 \pm 0,58$ \\
\hline Média Definidos & $353,9 \pm 11,9$ & $318,1 \pm 10,4$ & $89,9 \pm 0,41$ & $64,8 \pm 0,35$ & $63,1 \pm 0,35$ \\
\hline $21 / 32 \mathrm{Ch} 11 / 32 \mathrm{Ne}$ & $406,8 \pm 11,9$ & $364,6 \pm 10,4$ & $89,7 \pm 0,41$ & $65,1 \pm 0,35$ & $63,5 \pm 0,35$ \\
\hline $21 / 32 \mathrm{Ne} 11 / 32 \mathrm{Ch}$ & $384,2 \pm 11,4$ & $343,7 \pm 10,0$ & $89,5 \pm 0,39$ & $65,8 \pm 0,33$ & $64,1 \pm 0,34$ \\
\hline Média 5ª Geração & $395,0 \pm 42,9$ & $354,2 \pm 37,7$ & $89,6 \pm 0,28$ & $65,5 \pm 0,24$ & $63,8 \pm 0,24$ \\
\hline Efeito heterótico G5 & $41,6 \pm 14,5^{*}$ & $36,0 \pm 12,7^{*}$ & $-0,31 \pm 0,50$ & $0,63 \pm 0,43$ & $0,71 \pm 0,43$ \\
\hline $43 / 64 \mathrm{Ch} 21 / 64 \mathrm{Ne}$ & $393,1 \pm 14,9$ & $351,6 \pm 13,1$ & $89,5 \pm 0,51$ & $65,5 \pm 0,44$ & $63,7 \pm 0,44$ \\
\hline $43 / 64 \mathrm{Ne} 21 / 64 \mathrm{Ch}$ & $391,0 \pm 17,7$ & $348,5 \pm 15,5$ & $89,2 \pm 0,61$ & $65,8 \pm 0,52$ & $64,1 \pm 0,52$ \\
\hline Média $6^{\mathrm{a}}$ Geração & $392,2 \pm 34,0$ & $350,1 \pm 29,3$ & $89,4 \pm 0,40$ & $65,6 \pm 1,31$ & $63,9 \pm 0,34$ \\
\hline Efeito heterótico G6 & $38,1 \pm 16,6^{*}$ & $31,9 \pm 14,5^{*}$ & $-0,55 \pm 0,57$ & $0,77 \pm 0,49$ & $0,78 \pm 0,49$ \\
\hline \multicolumn{6}{|l|}{ Diferenças } \\
\hline Cruzados e Ch & $14,7 \pm 15,0$ & $9,73 \pm 13,1$ & $-0,88 \pm 0,52$ & $1,02 \pm 0,44^{*}$ & $1,02 \pm 0,44^{*}$ \\
\hline Cruzados e $\mathrm{Ne}$ & $65,0 \pm 21,0^{*}$ & $58,2 \pm 18,4^{*}$ & $0,01 \pm 0,72$ & $0,38 \pm 0,62$ & $0,47 \pm 0,62$ \\
\hline
\end{tabular}

a,b Médias seguidas por letras diferentes na mesma geração diferem com $\mathrm{P}<0,05$ pelo teste "t" de Student ; * $\mathrm{P}<0,05$

Do mesmo modo, para os rendimentos de carcaça quente e fria em relação ao peso de corpo vazio houve similitude entre os genótipos avaliados. Cattelan et al. $^{16}$ relataram similaridade nos rendimentos de carcaças quente e fria em relação ao peso de corpo vazio em bovinos de predominância racial Charolês ou Nelore após observaram rendimentos médios de 64,75 e 64,07\%, respectivamente. Porém, nas diferenças entre mestiços e definidos verificou-se que os novilhos cruzados foram $1,02 \%$ superiores ao Charolês nos rendimentos acima citados. Esse resultado demonstra como o incremento de genótipo zebuíno promove aumento no rendimento de carcaça, fato que pode ser comprovado quando se observa a correlação inversamente proporcional do total de componentes periféricos com os rendimentos das carcaças quente $(r=-0,31 ; P=0,0327)$ e fria $(r=-0,28 ; P=0,0537)$ em relação ao peso de corpo vazio. Restle et al. ${ }^{17}$ verificaram que o aumento da participação da raça Nelore no cruzamento com Hereford promoveu aumento no rendimento de carcaça fria dos bovinos.

Quanto aos componentes externos à carcaça (Tabela 2), verificou-se efeito heterótico de 1,29 e $1,04 \mathrm{~kg}$ na quinta e sexta gerações, respectivamente, para o peso absoluto de cabeça. De acordo com Missio et $a^{2}{ }^{2}$, a cabeça é desossada e a carne destinada principalmente à produção e 
comercialização na forma de carne moída, produção de embutidos e alimentos processados. Silva Sobrinho et al. ${ }^{18}$ ressaltam que os componentes nãocarcaça são constituídos de partes comestíveis, próprios à alimentação humana, sendo que a racionalização de seus usos pode evitar perdas, maximizando os ganhos econômicos e elevando a oferta de proteína de origem animal às populações carentes.

Ainda na Tabela 2, verifica-se que, com relação aos demais componentes externos à carcaça, para o componente couro, expresso em relação ao peso de corpo vazio, o efeito heterótico foi significativo, com valores de $-0,55$ e $-0,47 \%$ na quinta e sexta gerações do cruzamento, respectivamente. Menezes et al. ${ }^{10}$ observaram heterose de $-9,44 \%$ no peso do couro em relação ao peso de corpo vazio apenas nos novilhos de terceira geração do cruzamento entre as raças Charolês e Nelore. Ainda com relação ao couro, verificou-se que entre os animais definidos, os novilhos da raça Nelore apresentaram maior peso ajustado em relação aos animais Charolês $(9,78$ contra $8,42 \mathrm{~kg} / 100 \mathrm{~kg}$ de corpo vazio), assim como na sexta geração do cruzamento os bovinos $43 / 64 \mathrm{Ne} 21 / 64 \mathrm{Ch}$ foram superiores aos 43/64Ch $21 / 64 \mathrm{Ne}(9,24$ contra 8,01 $\mathrm{kg} / 100 \mathrm{~kg}$ de corpo vazio).

Maior peso ajustado de couro em animais com predomínio racial Nelore em relação a animais de predominância Charolês foi relatado por Pacheco et al. $^{7}$ e Cattelan et al. ${ }^{16}$, os quais citam que a superioridade dos animais zebuínos no componente couro deve estar relacionada ao maior desenvolvimento de giba e barbela desses animais, assim como ao maior comprimento dos membros, requerendo maior quantidade desse tecido para recobrir sua superfície corporal. Menezes et al. ${ }^{19}$, ao avaliarem as medidas corporais de novilhos, verificaram que as diferenças entre animais mestiços e definidos da raça Charolês foram significativas e positivas nas alturas de cernelha e garupa, demonstrando maior ímpeto de crescimento dos bovinos com genótipo Nelore, fato que auxilia em explicar o maior peso de couro os animais zebuínos em função do maior desenvolvimento dos membros anteriores e posteriores dos novilhos, requerendo maior desenvolvimento do couro para recobrimento dos membros.

$\mathrm{O}$ incremento que a participação da raça Nelore promove no couro fica evidenciado quando se observa que os cruzados foram $-1,19 \%$ inferiores aos novilhos Nelore no peso de couro em relação ao peso de corpo vazio. Pacheco et al. ${ }^{7}$ relataram que o couro é dos subprodutos de maior interesse pelos frigoríficos, em virtude do valor que pode ser agregado após seu beneficiamento, principalmente por indústrias calçadistas e de vestuário.

Quando os componentes da Tabela 2 são avaliados dentro das gerações do cruzamento, os novilhos definidos da raça Charolês apresentaram maior peso de cabeça $(13,1$ contra $10,9 \mathrm{~kg})$ e orelha $(0,78$ contra $0,25 \mathrm{~kg})$ em relação aos animais da raça Nelore, concordando com o resultado de Menezes et al. ${ }^{10}$. Ao avaliarem o peso conjunto de cabeça e orelhas, Kuss et al. ${ }^{8}$ verificaram que os animais com predominância racial Charolês de segunda geração do cruzamento com a raça Nelore apresentaram pesos superiores às fêmeas de predomínio zebuíno $(16,59$ contra $14,91 \mathrm{~kg})$, atribuindo o resultado à participação de $75 \%$ de sangue Charolês no genótipo.

Quanto aos componentes do trato digestório (Tabela 3), expressos em peso absoluto, houve efeito heterótico para rúmen-retículo na quinta e sexta gerações, com valores de 0,84 e $0,73 \mathrm{~kg}$, respectivamente, e para os intestinos, com valores de 1,26 e $0,93 \mathrm{~kg}$, citados na mesma ordem, e também efeito heterótico de $0,18 \mathrm{~kg}$ para o abomaso na quinta geração. O aumento nos pesos dos órgãos responsáveis pela digestão deve estar relacionado ao maior potencial de consumo dos novilhos mestiços em relação aos definidos, que acabou acarretando em maior desenvolvimento dos órgãos responsáveis pela digestão. De acordo com Signoretti et al. ${ }^{20}$, o trato gastrintestinal e seus órgãos têm, como funções básicas, a digestão e absorção de nutrientes, estando entre os tecidos de maior atividade metabólica nos animais ${ }^{21}$.

Para o peso dos intestinos, observou-se que, entre os novilhos definidos assim como entre os cruzados, os novilhos com predomínio Charolês no genótipo apresentaram maiores pesos absolutos e também em relação ao peso de corpo vazio. Ao avaliarem as características dos órgãos do trato digestório de novilhos superprecoces de diferentes genótipos e condições sexuais, Cattelam et al. ${ }^{5}$ verificaram maior peso de intestinos $(8,16 \mathrm{~kg})$ para animais de predomínio racial Charolês em relação a animais de predominância Nelore, para os quais esse componente pesou $6,84 \mathrm{~kg}$. Menezes et al. ${ }^{9}$ verificaram maior peso de intestinos em novilhos Charolês, atribuindo o resultado à maior seletividade dos animais pela fração concentrada da dieta. Ferrel et al. $^{22}$ ressaltaram que $\mathrm{o}$ maior peso dos constituintes do trato gastrintestinal está associado ao maior consumo de nutrientes e, consequentemente, ao maior aporte de nutrientes, visto que esses participam ativamente dos processos de digestão e absorção. 
Tabela 2 - Efeito heterótico e diferença entre novilhos cruzados e definidos para os componentes externos a carcaça de novilhos de diferentes genótipos e gerações do cruzamento entre as raças Charolês e Nelore

\begin{tabular}{|c|c|c|c|c|c|c|c|c|c|c|}
\hline \multirow{3}{*}{ Grupo Genético } & \multicolumn{10}{|c|}{ Componentes externos } \\
\hline & \multicolumn{2}{|c|}{ Cabeça } & \multicolumn{2}{|c|}{ Orelhas } & \multicolumn{2}{|c|}{ Patas } & \multicolumn{2}{|c|}{ Vassoura da cauda } & \multicolumn{2}{|c|}{ Couro } \\
\hline & $\mathrm{Kg}$ & $\begin{array}{l}\% \text { Peso de } \\
\text { corpo vazio }\end{array}$ & $\mathrm{Kg}$ & $\begin{array}{l}\% \text { Peso de } \\
\text { corpo vazio }\end{array}$ & $\mathrm{Kg}$ & $\begin{array}{l}\% \text { Peso de } \\
\text { corpo vazio }\end{array}$ & $\mathrm{Kg}$ & $\begin{array}{l}\% \text { Peso de } \\
\text { corpo vazio }\end{array}$ & $\mathrm{Kg}$ & $\begin{array}{l}\% \text { Peso de } \\
\text { corpo vazio }\end{array}$ \\
\hline Charolês & $13,1 \pm 035 \mathrm{a}$ & $3,83 \pm 0,08$ & $0,78 \pm 0,06 \mathrm{a}$ & $0,23 \pm 0,01 \mathrm{a}$ & $8,45 \pm 0,05$ & $2,46 \pm 0,16$ & $0,26 \pm 0,04$ & $0,07 \pm 0,01$ & $28,8 \pm 0,99$ & $8,42 \pm 0,18 b$ \\
\hline Nelore & $10,9 \pm 0,53 \mathrm{~b}$ & $3,69 \pm 0,12$ & $0,25 \pm 0,09 \mathrm{~b}$ & $0,09 \pm 0,01 \mathrm{~b}$ & $7,27 \pm 0,08$ & $2,49 \pm 0,18$ & $0,12 \pm 0,07$ & $0,04 \pm 0,01$ & $28,7 \pm 1,49$ & $9,78 \pm 0,28 \mathrm{a}$ \\
\hline Média Definidos & $12,0 \pm 0,32$ & $3,76 \pm 0,07$ & $0,52 \pm 0,05$ & $0,16 \pm 0,01$ & $7,86 \pm 0,25$ & $2,47 \pm 0,05$ & $0,19 \pm 0,04$ & $0,06 \pm 0,01$ & $28,8 \pm 0,90$ & $9,10 \pm 0,17$ \\
\hline $21 / 32 \mathrm{Ch} 11 / 32 \mathrm{Ne}$ & $13,7 \pm 0,32$ & $3,75 \pm 0,07$ & $0,71 \pm 0,05$ & $0,20 \pm 0,01$ & $8,38 \pm 0,05$ & $2,30 \pm 0,14$ & $0,23 \pm 0,04$ & $0,06 \pm 0,01$ & $30,7 \pm 0,90$ & $8,43 \pm 0,17$ \\
\hline $21 / 32 \mathrm{Ne} 11 / 32 \mathrm{Ch}$ & $12,9 \pm 0,31$ & $3,78 \pm 0,07$ & $0,67 \pm 0,05$ & $0,19 \pm 0,01$ & $8,40 \pm 0,05$ & $2,45 \pm 0,16$ & $0,15 \pm 0,04$ & $0,04 \pm 0,01$ & $29,7 \pm 0,86$ & $8,67 \pm 0,16$ \\
\hline Média $5^{\mathrm{a}}$ Geração & $13,3 \pm 0,22$ & $3,77 \pm 0,24$ & $0,69 \pm 0,04$ & $0,20 \pm 0,01$ & $8,39 \pm 0,17$ & $2,38 \pm 0,17$ & $0,19 \pm 0,03$ & $0,05 \pm 0,01$ & $30,2 \pm 0,62$ & $8,55 \pm 0,12$ \\
\hline Efeito heterótico G5 & $1,29 \pm 0,39^{*}$ & $0,00 \pm 0,09$ & $0,17 \pm 0,07^{*}$ & $0,04 \pm 0,02^{*}$ & $0,52 \pm 0,30$ & $-0,10 \pm 0,06$ & $0,00 \pm 0,05$ & $-0,01 \pm 0,01$ & $1,45 \pm 1,09$ & $-0,55 \pm 0,20 *$ \\
\hline $43 / 64 \mathrm{Ch} 21 / 64 \mathrm{Ne}$ & $13,3 \pm 0,40$ & $3,80 \pm 0,09$ & $0,61 \pm 0,07$ & $0,17 \pm 0,02$ & $8,17 \pm 0,06$ & $2,33 \pm 0,23$ & $0,15 \pm 0,05$ & $0,04 \pm 0,01$ & $28,1 \pm 1,13$ & $8,01 \pm 0,21 b$ \\
\hline $43 / 64 \mathrm{Ne} 21 / 64 \mathrm{Ch}$ & $12,7 \pm 0,48$ & $3,66 \pm 0,11$ & $0,68 \pm 0,08$ & $0,19 \pm 0,02$ & $8,28 \pm 0,07$ & $2,38 \pm 0,15$ & $0,19 \pm 0,07$ & $0,05 \pm 0,01$ & $32,2 \pm 1,33$ & $9,24 \pm 0,25 \mathrm{a}$ \\
\hline Média $6^{a}$ Geração & $13,0 \pm 0,31$ & $3,73 \pm 0,07$ & $0,65 \pm 0,05$ & $0,18 \pm 0,01$ & $8,22 \pm 0,24$ & $2,35 \pm 0,19$ & $0,17 \pm 0,04$ & $0,05 \pm 0,01$ & $30,1 \pm 0,87$ & $8,62 \pm 0,16$ \\
\hline Efeito heterótico G6 & $1,04 \pm 0,44^{*}$ & $-0,03 \pm 0,10$ & $0,12 \pm 0,08$ & $0,02 \pm 0,02$ & $0,36 \pm 0,35$ & $-0,12 \pm 0,07$ & $-0,01 \pm 0,06$ & $-0,01 \pm 0,01$ & $1,41 \pm 1,25$ & $-0,47 \pm 0,23 *$ \\
\hline \multicolumn{11}{|l|}{ Diferenças } \\
\hline Cruzados e Ch & $0,06 \pm 0,40$ & $-0,08 \pm 0,09$ & $-0,11 \pm 0,07$ & $-0,03 \pm 0,02$ & $-0,14 \pm 0,31$ & $-0,09 \pm 0,06$ & $-0,07 \pm 0,05$ & $-0,02 \pm 0,01$ & $1,35 \pm 1,13$ & $0,16 \pm 0,21$ \\
\hline Cruzados e Ne & $2,28 \pm 0,57^{*}$ & $0,06 \pm 0,13$ & $0,42 \pm 0,10^{*}$ & $0,10 \pm 0,03^{*}$ & $1,03 \pm 0,44^{*}$ & $-0,12 \pm 0,09$ & $0,06 \pm 0,07$ & $0,01 \pm 0,02$ & $1,51 \pm 1,58$ & $-1,19 \pm 0,30^{*}$ \\
\hline
\end{tabular}

Tabela 3 - Efeito heterótico e diferença entre novilhos cruzados e definidos para os componentes do trato digestório de novilhos de diferentes genótipos e gerações do cruzamento entre as raças Charolês e Nelore

\begin{tabular}{|c|c|c|c|c|c|c|c|c|}
\hline \multirow{3}{*}{ Grupo Genético } & \multicolumn{8}{|c|}{ Trato Digestório } \\
\hline & \multicolumn{2}{|c|}{ Rumén-reticulo } & \multicolumn{2}{|c|}{ Omaso } & \multicolumn{2}{|c|}{ Abomaso } & \multicolumn{2}{|c|}{ Intestinos } \\
\hline & $\mathrm{kg}$ & $\begin{array}{l}\% \text { Peso de } \\
\text { corpo vazio }\end{array}$ & $\mathrm{kg}$ & $\begin{array}{l}\% \text { Peso de } \\
\text { corpo vazio }\end{array}$ & $\mathrm{kg}$ & $\begin{array}{l}\% \text { Peso de } \\
\text { corpo vazio }\end{array}$ & $\mathrm{kg}$ & $\begin{array}{l}\% \text { Peso de } \\
\text { corpo vazio }\end{array}$ \\
\hline Charolês & $5,62 \pm 0,25$ & $1,64 \pm 0,04$ & $3,21 \pm 0,21$ & $0,93 \pm 0,04$ & $1,32 \pm 0,08$ & $0,38 \pm 0,02$ & $8,35 \pm 0,34 \mathrm{a}$ & $2,44 \pm 0,07 \mathrm{a}$ \\
\hline Nelore & $4,70 \pm 0,38$ & $1,60 \pm 0,06$ & $2,58 \pm 0,31$ & $0,88 \pm 0,07$ & $0,98 \pm 0,12$ & $0,33 \pm 0,02$ & $5,70 \pm 0,51 \mathrm{~b}$ & $1,94 \pm 0,10 \mathrm{~b}$ \\
\hline Média Definidos & $5,16 \pm 0,23$ & $1,63 \pm 0,04$ & $2,89 \pm 0,19$ & $0,91 \pm 0,04$ & $1,15 \pm 0,07$ & $0,36 \pm 0,01$ & $7,03 \pm 0,31$ & $2,19 \pm 0,06$ \\
\hline $21 / 32 \mathrm{Ch} 11 / 32 \mathrm{Ne}$ & $6,22 \pm 0,23$ & $1,70 \pm 0,04$ & $3,41 \pm 0,19$ & $0,93 \pm 0,04$ & $1,40 \pm 0,07$ & $0,38 \pm 0,01$ & $8,87 \pm 0,31 \mathrm{a}$ & $2,44 \pm 0,06 \mathrm{a}$ \\
\hline $21 / 32 \mathrm{Ne} 11 / 32 \mathrm{Ch}$ & $5,79 \pm 0,22$ & $1,68 \pm 0,03$ & $3,10 \pm 0,18$ & $0,90 \pm 0,04$ & $1,28 \pm 0,07$ & $0,37 \pm 0,01$ & $7,70 \pm 0,30 \mathrm{~b}$ & $2,24 \pm 0,06 \mathrm{~b}$ \\
\hline Média 5a Geração & $6,01 \pm 0,16$ & $1,69 \pm 0,11$ & $3,26 \pm 0,13$ & $0,92 \pm 0,03$ & $1,34 \pm 0,05$ & $0,37 \pm 0,01$ & $8,29 \pm 0,21$ & $2,34 \pm 0,04$ \\
\hline Efeito heterótico G5 & $0,84 \pm 0,28^{*}$ & $0,07 \pm 0,04$ & $0,36 \pm 0,23$ & $0,00 \pm 0,05$ & $0,18 \pm 0,08^{*}$ & $0,01 \pm 0,02$ & $1,26 \pm 0,38^{*}$ & $0,14 \pm 0,07$ \\
\hline $43 / 64 \mathrm{Ch} 21 / 64 \mathrm{Ne}$ & $5,95 \pm 0,29$ & $1,69 \pm 0,04$ & $3,10 \pm 0,23$ & $0,88 \pm 0,05$ & $1,31 \pm 0,09$ & $0,37 \pm 0,02$ & $8,57 \pm 0,39 a$ & $2,44 \pm 0,07 \mathrm{a}$ \\
\hline $43 / 64 \mathrm{Ne} 21 / 64 \mathrm{Ch}$ & $5,85 \pm 0,34$ & $1,67 \pm 0,05$ & $3,52 \pm 0,28$ & $1,00 \pm 0,06$ & $1,21 \pm 0,10$ & $0,34 \pm 0,02$ & $7,34 \pm 0,46 \mathrm{~b}$ & $2,10 \pm 0,09 \mathrm{~b}$ \\
\hline Média 6a Geração & $5,90 \pm 0,22$ & $1,68 \pm 0,04$ & $3,31 \pm 0,18$ & $0,94 \pm 0,04$ & $1,26 \pm 0,07$ & $0,36 \pm 0,01$ & $7,95 \pm 0,30$ & $2,27 \pm 0,06$ \\
\hline Efeito heterótico G6 & $0,73 \pm 0,32^{*}$ & $0,06 \pm 0,05$ & $0,41 \pm 0,26$ & $0,03 \pm 0,06$ & $0,10 \pm 0,10$ & $-0,01 \pm 0,02$ & $0,93 \pm 0,43^{*}$ & $0,07 \pm 0,08$ \\
\hline \multicolumn{9}{|l|}{ Diferenças } \\
\hline Cruzados e Ch & $0,32 \pm 0,29$ & $0,04 \pm 0,04$ & $0,07 \pm 0,24$ & $-0,01 \pm 0,05$ & $-0,02 \pm 0,09$ & $-0,02 \pm 0,02$ & $-0,22 \pm 0,39$ & $-0,13 \pm 0,07$ \\
\hline Cruzados e Ne & $1,25 \pm 0,40^{*}$ & $0,09 \pm 0,07$ & $0,69 \pm 0,33^{*}$ & $0,05 \pm 0,07$ & $0,31 \pm 0,12^{*}$ & $0,03 \pm 0,03$ & $2,41 \pm 0,55^{*}$ & $0,36 \pm 0,11^{*}$ \\
\hline
\end{tabular}

a,b Médias seguidas por letras diferentes na mesma geração diferem com $\mathrm{P}<0,05$ pelo teste " $\mathrm{t}$ " de Student

* $\mathrm{P}<0,05$

Quanto às diferenças entre os novilhos cruzados e definidos, observou-se que os animais mestiços apresentaram maiores pesos que os bovinos definidos da raça Nelore para todos os constituintes do trato digestório, sendo superiores 1,$25 ; 0,69 ; 0,31 \mathrm{e}$ $2,41 \mathrm{~kg}$ nos pesos de rúmen- retículo, omaso, abomaso e intestinos, respectivamente. De acordo com Menezes et al..$^{23}$ o peso do trato digestório é maior em bovinos com predominância de raça taurina em relação a animais com predomínio genético zebuíno.

Quanto aos órgãos internos (Tabela 4), em peso absoluto, verificou-se efeito heterótico significativo na quinta geração para o coração, 
pulmões, rins e baço, com valores de 0,$14 ; 0,11 ; 0,55$ e $0,16 \mathrm{~kg}$, respectivamente, e também na sexta geração para os pulmões, com efeito heterótico de $0,61 \mathrm{~kg}$, resultado que deve estar atrelado ao aumento nos pesos de abate e de corpo vazio dos novilhos (Tabela 1), sendo necessário incremento no tamanho dos órgãos em virtude do aumento da taxa metabólica. Para Kuss et al. ${ }^{1}$, bovinos destinados à produção de carne, como o caso da raça Charolês, selecionados para altas taxas de ganho de peso, apresentam maior consumo de alimento, sendo necessário aumento simultâneo dos órgãos responsáveis pelo metabolismo basal. Esse resultado discorda do observado por Menezes et al. ${ }^{9}$, que não encontraram heterose significativa em nenhuma das gerações avaliadas. Quando os órgãos internos foram analisados em relação ao peso de corpo vazio, o efeito heterótico não foi significativo em nenhuma das gerações avaliadas. Porém esses autores observaram heterose negativa e significativa nos pesos ajustados em relação ao peso de corpo vazio para coração $(-18,29 \%)$ e rins ($14,29 \%$ ) na terceira geração, e para pulmões ($13,45 \%$ ) na quarta geração do cruzamento entre as raças Charolês e Nelore.

Entre as gerações do cruzamento estudadas, nos novilhos definidos, os animais Charolês apresentaram peso de fígado $26,8 \%$ superior aos novilhos Nelore. Menezes et al. ${ }^{9}$ também verificaram maior peso de fígado em novilhos Charolês em comparação a bovinos Nelore, fato que os autores associaram ao maior consumo de matéria seca e energia digestível daqueles animais, em virtude da seleção pela fração concentrada da dieta. Segundo Owens et al. $^{24}$, o fígado participa ativamente do metabolismo de nutrientes, estando sua atividade intimamente relacionada ao consumo de nutrientes, assim, espera-se que no presente estudo está superioridade deva estar relacionada à seleção pela fração mais energética.

Também o peso do baço foi maior nos bovinos definidos Charolês em relação aos Nelore em peso absoluto (1,32 contra $0,91 \mathrm{~kg})$, assim como no peso ajustado $(0,37$ contra $0,31 \mathrm{~kg} / 100 \mathrm{~kg}$ de peso de corpo vazio), o qual também diferiu, em peso absoluto, entre os genótipos da quinta geração, tendo os novilhos de predomínio racial taurino demonstrado maiores pesos em comparação aos de predominância zebuína (1,37 contra $1,15 \mathrm{~kg})$. Ao avaliar as vísceras de bovinos Nelore e F1 Nelore x Sindi, Costa et al. ${ }^{25}$ verificaram que os bovinos mestiços apresentaram menores pesos de coração $(1,2$ contra $1,6 \mathrm{~kg})$ e de baço $(0,9$ contra $1,1 \mathrm{~kg})$. Esses autores ressaltaram que o menor desenvolvimento desses órgãos resulta em menores taxas metabólicas, o que leva a menores necessidades energéticas. Ainda na Tabela 4, verificase que os novilhos mestiços foram superiores aos bovinos da raça Nelore para todos os órgãos internos, expresso em $\mathrm{kg}$, porém não é observada diferença quando esses órgãos são expressos em relação ao peso de corpo vazio. Do mesmo modo, Menezes et al. ${ }^{9}$ não verificaram diferença quando o peso dos órgãos internos foi ajustado ao peso de corpo vazio, entre novilhos mestiços e definidos Nelore, ao passo que Kuss et al. ${ }^{1}$ observaram diferença entre fêmeas de descarte de predominância racial Charolês ou Nelore apenas para o peso ajustado dos pulmões.

Para os diferentes tipos de gorduras estudadas (Tabela 5), quando analisadas em peso absoluto, o efeito heterótico foi significativo, sendo de 0,$05 ; 0,77$ e $1,98 \mathrm{~kg}$ para gorduras de coração, renal e do trato digestório, respectivamente, na quinta geração, e de 0,$09 ; 1,02 ; 0,44$ e $1,85 \mathrm{~kg}$, para as gorduras de coração, renal, inguinal e do trato digestório, citados na mesma ordem, na sexta geração do cruzamento. Ao avaliarem bovinos de diferentes gerações do cruzamento entre as raças Charolês e Nelore, Menezes et al. ${ }^{10}$ observaram que a heterose foi significativa na segunda geração para as gorduras renal $(39,88 \%)$ e intestinal $(43,96 \%)$ e na quarta geração para gordura ruminal $(41,48 \%)$. Entretanto, quando esses autores ajustaram as gorduras para o peso de corpo vazio, a heterose permaneceu significativa na segunda geração para gordura intestinal $(28,06 \%)$ e foi significativa na quarta geração para gordura de toalete $(-21,67 \%)$. No presente estudo, o efeito heterótico foi significativo apenas para a gordura de coração ajustada ao peso de corpo vazio, sendo de $0,02 \%$ na sexta geração.

Segundo os últimos autores acima citados, para as gorduras descartadas são desejáveis heteroses negativas, visto que as mesmas prejudicam o rendimento de carcaça. A gordura depositada internamente tem maior atividade metabólica que o tecido adiposo periférico, o que acarreta em aumento nos requerimentos de energia de mantença de animais com maiores depósitos de gordura interna ${ }^{26}$. Conforme Di Marco ${ }^{27}$ a gordura visceral acumulada é um desperdício que não agrega peso à carcaça e afeta a eficiência do animal em converter alimento, sendo inevitável seu acúmulo quando avança o grau de terminação dos animais.

Para a gordura de toalete, que é o excesso de tecido adiposo retirado da carcaça, houve diferença entre os novilhos definidos e dentro de cada geração do cruzamento, tendo os animais da raça Charolês e mestiços com predominância taurina maiores pesos dessa gordura. O excesso de deposição sobre a carcaça acarreta menor lucratividade, visto que essa gordura é retirada antes da pesagem das carcaças, não gerando remuneração ao produtor. Menezes et al. ${ }^{10}$ também observaram maior peso absoluto para gordura de toalete em novilhos da raça Charolês $(2,85 \mathrm{~kg})$ em comparação a animais da raça Nelore 
$(1,30 \mathrm{~kg})$, porém não foi significativa nas demais gerações do cruzamento. Quando expressa em relação a peso de corpo vazio, não houve diferença entre os genótipos estudados, concordando com os resultados observados por Kuss et al..$^{5}$ em fêmeas de descarte da segunda e terceira gerações do cruzamento entre as raças Charolês e Nelore.

Tabela 4 - Efeito heterótico e diferença entre novilhos cruzados e definidos para os órgãos internos de novilhos de diferentes genótipos e gerações do cruzamento entre as raças Charolês e Nelore

\begin{tabular}{|c|c|c|c|c|c|c|c|c|c|c|}
\hline \multirow{3}{*}{ Grupo Genético } & \multicolumn{10}{|c|}{ Órgãos Internos } \\
\hline & \multicolumn{2}{|c|}{ Coração } & \multicolumn{2}{|c|}{ Rins } & \multicolumn{2}{|c|}{ Pulmões } & \multicolumn{2}{|c|}{ Figado } & \multicolumn{2}{|c|}{ Baço } \\
\hline & $\mathrm{Kg}$ & $\begin{array}{l}\% \text { Peso de } \\
\text { corpo vazio }\end{array}$ & $\mathrm{Kg}$ & $\begin{array}{l}\% \text { Peso de } \\
\text { corpo vazio }\end{array}$ & $\mathrm{Kg}$ & $\begin{array}{l}\% \text { Peso de } \\
\text { corpo vazio }\end{array}$ & $\mathrm{Kg}$ & $\begin{array}{l}\text { \% Peso de } \\
\text { corpo vazio }\end{array}$ & $\mathrm{kg}$ & $\begin{array}{l}\% \text { Peso de } \\
\text { corpo vazio }\end{array}$ \\
\hline Charolês & $1,22 \pm 0,05$ & $0,36 \pm 0,01$ & $0,80 \pm 0,04$ & $0,23 \pm 0,01$ & $5,07 \pm 0,21$ & $1,48 \pm 0,04$ & $5,05 \pm 0,22 \mathrm{a}$ & $1,47 \pm 0,04$ & $1,32 \pm 0,07 a$ & $0,37 \pm 0,01 \mathrm{a}$ \\
\hline Nelore & $0,99 \pm 0,08$ & $0,33 \pm 0,02$ & $0,66 \pm 0,07$ & $0,22 \pm 0,01$ & $4,27 \pm 0,32$ & $1,45 \pm 0,06$ & $3,98 \pm 0,33 \mathrm{~b}$ & $1,35 \pm 0,05$ & $0,91 \pm 0,10 \mathrm{~b}$ & $0,31 \pm 0,01 \mathrm{~b}$ \\
\hline Média Definidos & $1,11 \pm 0,05$ & $0,35 \pm 0,01$ & $0,73 \pm 0,04$ & $0,23 \pm 0,01$ & $4,67 \pm 0,19$ & $1,47 \pm 0,03$ & $4,51 \pm 0,20$ & $1,41 \pm 0,03$ & $1,10 \pm 0,06$ & $0,35 \pm 0,04$ \\
\hline $21 / 32 \mathrm{Ch} 11 / 32 \mathrm{Ne}$ & $1,30 \pm 0,05$ & $0,36 \pm 0,01$ & $0,89 \pm 0,04$ & $0,24 \pm 0,01$ & $5,43 \pm 0,19$ & $1,49 \pm 0,03$ & $5,00 \pm 0,20$ & $1,37 \pm 0,03$ & $1,37 \pm 0,06 \mathrm{a}$ & $0,37 \pm 0,01$ \\
\hline $21 / 32 \mathrm{Ne} 11 / 32 \mathrm{Ch}$ & $1,20 \pm 0,05$ & $0,35 \pm 0,01$ & $0,80 \pm 0,04$ & $0,23 \pm 0,01$ & $5,01 \pm 0,18$ & $1,46 \pm 0,03$ & $4,56 \pm 0,19$ & $1,32 \pm 0,03$ & $1,15 \pm 0,06 \mathrm{~b}$ & $0,33 \pm 0,01$ \\
\hline Média 5a Geração & $1,25 \pm 0,03$ & $0,35 \pm 0,01$ & $0,85 \pm 0,16$ & $0,24 \pm 0,01$ & $5,22 \pm 0,13$ & $1,47 \pm 0,02$ & $4,78 \pm 0,14$ & $1,34 \pm 0,02$ & $1,26 \pm 0,04$ & $0,35 \pm 0,01$ \\
\hline Efeito heterótico G5 & $0,14 \pm 0,06^{*}$ & $0,00 \pm 0,01$ & $0,11 \pm 0,05^{*}$ & $0,00 \pm 0,01$ & $0,55 \pm 0,23^{*}$ & $0,00 \pm 0,04$ & $0,26 \pm 0,24$ & $-0,07 \pm 0,04$ & $0,16 \pm 0,07^{*}$ & $0,01 \pm 0,02$ \\
\hline $43 / 64 \mathrm{Ch} 21 / 64 \mathrm{Ne}$ & $1,19 \pm 0,06$ & $0,34 \pm 0,01$ & $0,87 \pm 0,05$ & $0,25 \pm 0,01$ & $5,36 \pm 0,24$ & $1,52 \pm 0,04$ & $4,73 \pm 0,25$ & $1,34 \pm 0,04$ & $1,35 \pm 0,07$ & $0,38 \pm 0,02$ \\
\hline $43 / 64 \mathrm{Ne} 21 / 64 \mathrm{Ch}$ & $1,26 \pm 0,07$ & $0,36 \pm 0,02$ & $0,79 \pm 0,06$ & $0,22 \pm 0,01$ & $5,21 \pm 0,28$ & $1,48 \pm 0,05$ & $4,62 \pm 0,29$ & $1,33 \pm 0,05$ & $1,14 \pm 0,09$ & $0,32 \pm 0,02$ \\
\hline Média 6a Geração & $1,22 \pm 0,05$ & $0,35 \pm 0,01$ & $0,84 \pm 0,04$ & $0,24 \pm 0,01$ & $5,28 \pm 0,19$ & $1,51 \pm 0,03$ & $4,68 \pm 0,20$ & $1,33 \pm 0,03$ & $1,25 \pm 0,06$ & $0,36 \pm 0,01$ \\
\hline Efeito heterótico G6 & $0,11 \pm 0,07$ & $0,00 \pm 0,01$ & $0,10 \pm 0,06$ & $0,00 \pm 0,01$ & $0,61 \pm 0,27^{*}$ & $0,03 \pm 0,05$ & $0,16 \pm 0,28$ & $-0,08 \pm 0,04$ & $0,14 \pm 0,08$ & $0,01 \pm 0,02$ \\
\hline \multicolumn{11}{|l|}{ Diferenças } \\
\hline Cruzados e Ch & $0,01 \pm 0,06$ & $-0,01 \pm 0,01$ & $0,03 \pm 0,05$ & $0,00 \pm 0,01$ & $0,18 \pm 0,24$ & $0,00 \pm 0,04$ & $-0,32 \pm 0,25$ & $-0,13 \pm 0,04^{*}$ & $-0,04 \pm 0,07$ & $-0,02 \pm 0,02$ \\
\hline Cruzados e $\mathrm{Ne}$ & $0,24 \pm 0,09^{*}$ & $0,02 \pm 0,02$ & $0,17 \pm 0,07^{*}$ & $0,01 \pm 0,01$ & $0,98 \pm 0,34^{*}$ & $0,03 \pm 0,06$ & $0,74 \pm 0,35^{*}$ & $-0,01 \pm 0,06$ & $0,34 \pm 0,11^{*}$ & $0,05 \pm 0,02$ \\
\hline
\end{tabular}

${ }^{a, b}$ Médias seguidas por letras diferentes na mesma geração diferem com $\mathrm{P}<0,05$ pelo teste " $\mathrm{t}$ " de Student

$* \mathrm{P}<0,05$

Tabela 5 - Efeito heterótico e diferença entre novilhos cruzados e definidos para as gorduras descartadas de novilhos de diferentes genótipos e gerações do cruzamento entre as raças Charolês e Nelore

\begin{tabular}{|c|c|c|c|c|c|c|c|c|c|c|}
\hline \multirow{3}{*}{ Grupo Genético } & \multicolumn{10}{|c|}{ Gorduras } \\
\hline & \multicolumn{2}{|c|}{ Coração } & \multicolumn{2}{|c|}{ Renal } & \multicolumn{2}{|c|}{ Inguinal } & \multicolumn{2}{|c|}{ Trato digestório } & \multicolumn{2}{|c|}{ Toalete } \\
\hline & $\mathrm{Kg}$ & $\begin{array}{l}\% \text { Peso de } \\
\text { corpo vazio }\end{array}$ & $\mathrm{Kg}$ & $\begin{array}{l}\% \text { Peso de } \\
\text { corpo vazio }\end{array}$ & $\mathrm{Kg}$ & $\begin{array}{l}\% \text { Peso de } \\
\text { corpo vazio }\end{array}$ & $\mathrm{Kg}$ & $\begin{array}{l}\% \text { Peso de } \\
\text { corpo vazio }\end{array}$ & $\mathrm{kg}$ & $\begin{array}{l}\% \text { Peso de } \\
\text { corpo vazio }\end{array}$ \\
\hline Charolês & $0,15 \pm 0,03$ & $0,04 \pm 0,01$ & $3,72 \pm 0,34$ & $1,09 \pm 0,09$ & $1,81 \pm 0,14$ & $0,53 \pm 0,03 \mathrm{~b}$ & $10,6 \pm 0,61$ & $3,09 \pm 0,14$ & $2,77 \pm 0,06$ & $0,81 \pm 0,20$ \\
\hline Nelore & $0,14 \pm 0,05$ & $0,05 \pm 0,01$ & $3,20 \pm 0,52$ & $1,08 \pm 0,14$ & $2,21 \pm 0,21$ & $0,75 \pm 0,05 \mathrm{a}$ & $8,87 \pm 0,91$ & $3,01 \pm 0,21$ & $2,04 \pm 0,09$ & $0,76 \pm 0,24$ \\
\hline Média Definidos & $0,15 \pm 0,03$ & $0,04 \pm 0,01$ & $3,46 \pm 0,31$ & $1,09 \pm 0,08$ & $2,01 \pm 0,13$ & $0,64 \pm 0,03$ & $9,72 \pm 0,55$ & $3,06 \pm 0,12$ & $2,41 \pm 0,21$ & $0,76 \pm 0,06$ \\
\hline $21 / 32 \mathrm{Ch} 11 / 32 \mathrm{Ne}$ & $0,22 \pm 0,03$ & $0,06 \pm 0,01$ & $4,58 \pm 0,31$ & $1,26 \pm 0,08$ & $2,22 \pm 0,13$ & $0,61 \pm 0,03$ & $11,9 \pm 0,55$ & $3,28 \pm 0,12$ & $2,74 \pm 0,06 \mathrm{a}$ & $0,75 \pm 0,17$ \\
\hline $21 / 32 \mathrm{Ne} 11 / 32 \mathrm{Ch}$ & $0,17 \pm 0,03$ & $0,05 \pm 0,01$ & $3,89 \pm 0,30$ & $1,12 \pm 0,08$ & $2,22 \pm 0,12$ & $0,64 \pm 0,03$ & $11,4 \pm 0,53$ & $3,32 \pm 0,12$ & $2,01 \pm 0,05 \mathrm{~b}$ & $0,58 \pm 0,10$ \\
\hline Média $5^{\mathrm{a}}$ Geração & $0,20 \pm 0,04$ & $0,05 \pm 0,01$ & $4,24 \pm 0,21$ & $1,19 \pm 0,06$ & $2,22 \pm 0,09$ & $0,63 \pm 0,02$ & $11,7 \pm 0,38$ & $3,30 \pm 0,08$ & $2,38 \pm 0,14$ & $0,67 \pm 0,04$ \\
\hline Efeito heterótico G5 & $0,05 \pm 0,03^{*}$ & $0,01 \pm 0,01$ & $0,77 \pm 0,38^{*}$ & $0,10 \pm 0,10$ & $0,21 \pm 0,15$ & $-0,01 \pm 0,04$ & $1,98 \pm 0,67^{*}$ & $0,24 \pm 0,15$ & $-0,02 \pm 0,25$ & $-0,09 \pm 0,07$ \\
\hline $43 / 64 \mathrm{Ch} 21 / 64 \mathrm{Ne}$ & $0,29 \pm 0,03$ & $0,08 \pm 0,01$ & $4,72 \pm 0,39$ & $1,34 \pm 0,10$ & $2,20 \pm 0,16$ & $0,62 \pm 0,03 \mathrm{~b}$ & $11,7 \pm 0,69$ & $3,33 \pm 0,15$ & $2,81 \pm 0,07 a$ & $0,79 \pm 0,22$ \\
\hline $43 / 64 \mathrm{Ne} 21 / 64 \mathrm{Ch}$ & $0,20 \pm 0,04$ & $0,05 \pm 0,01$ & $4,25 \pm 0,46$ & $1,22 \pm 0,12$ & $2,71 \pm 0,19$ & $0,78 \pm 0,04 \mathrm{a}$ & $11,4 \pm 0,82$ & $3,26 \pm 0,18$ & $1,99 \pm 0,08 \mathrm{~b}$ & $0,59 \pm 0,30$ \\
\hline Média 6a Geração & $0,25 \pm 0,18$ & $0,06 \pm 0,04$ & $4,48 \pm 0,30$ & $1,29 \pm 0,08$ & $2,45 \pm 0,61$ & $0,70 \pm 0,03$ & $11,6 \pm 0,53$ & $3,30 \pm 0,42$ & $2,40 \pm 0,20$ & $0,69 \pm 0,06$ \\
\hline Efeito heterótico G6 & $0,09 \pm 0,04^{*}$ & $0,02 \pm 0,01^{*}$ & $1,02 \pm 0,43^{*}$ & $0,19 \pm 0,11$ & $0,44 \pm 0,18^{*}$ & $0,06 \pm 0,04$ & $1,85 \pm 0,77^{*}$ & $0,24 \pm 0,17$ & $-0,01 \pm 0,29$ & $-0,06 \pm 0,08$ \\
\hline \multicolumn{11}{|l|}{ Diferenças } \\
\hline Cruzados e Ch & $0,07 \pm 0,04^{*}$ & $0,02 \pm 0,01$ & $0,63 \pm 0,39$ & $0,14 \pm 0,11$ & $0,52 \pm 0,16^{*}$ & $0,13 \pm 0,04^{*}$ & $1,06 \pm 0,69$ & $0,20 \pm 0,15$ & $-0,37 \pm 0,26$ & $-0,13 \pm 0,07$ \\
\hline Cruzados e Ne & $0,08 \pm 0,05^{*}$ & $0,01 \pm 0,01$ & $1,16 \pm 0,55^{*}$ & $0,15 \pm 0,15$ & $0,12 \pm 0,23$ & $-0,08 \pm 0,06$ & $2,76 \pm 0,97^{*}$ & $0,28 \pm 0,22$ & $0,35 \pm 0,36$ & $-0,02 \pm 0,10$ \\
\hline
\end{tabular}

* $\mathrm{P}<0,05$

Para o conjunto dos componentes externos (Tabela 6), o efeito heterótico foi de $3,45 \mathrm{~kg}$ na quinta geração e de $-0,61 \%$ em ambas as gerações, quando esses efeitos foram expressos em relação ao peso de corpo vazio. De acordo com Kuss et al. ${ }^{5}$, menores participações dos componentes externos no peso de corpo vazio promovem elevação do peso e rendimento de carcaça. Esses autores verificaram correlações de $-0,82(\mathrm{P}=0,0001)$ e $-0,47(\mathrm{P}=0,0202)$ entre o peso e rendimento de carcaça quente com o 
conjunto dos componentes externos ajustados ao peso de corpo vazio. Neste estudo, quando ajustados ao peso de corpo vazio, os componentes externos correlacionaram-se com os rendimentos de carcaça quente $(\mathrm{r}=-0,34 ; \mathrm{P}=0,0188)$ e fria $(\mathrm{r}=-0,33$; $\mathrm{P}=0,0210)$ em relação ao peso de abate (Tabela 7). Ainda com relação aos componentes externos, quando expressos em relação ao peso de corpo vazio, os novilhos de predomínio racial Charolês foram superiores entre os definidos e na sexta geração, influenciados pela superioridade nos componentes orelhas e couro.

Quanto ao total de constituintes do trato digestório, em peso absoluto, houve efeito heterótico significativo na quinta e sexta gerações do cruzamento, com valores de $2,65 \mathrm{~kg}$ e $2,18 \mathrm{~kg}$, respectivamente, o que está associado aos efeitos heterótico no rúmen-retículo, abomaso e intestinos (Tabela 3). Também houve diferença nas gerações do cruzamento, tendo os novilhos Charolês, entre os definidos, e os de predomínio genético taurino, na quinta geração, apresentado maiores pesos do trato digestório. Ferrel \& Jenkins ${ }^{28}$ verificaram maior peso do trato gastrintestinal em bovinos das raças Angus e Hereford em relação a animais da raça Brahman, associando o resultado ao menor potencial de consumo dos bovinos zebuínos. Menezes et al. ${ }^{23}$ relataram maior peso do trato digestório em bovinos com predominância taurina em relação aos animais zebuínos.

Houve efeito heterótico para o total de órgãos internos na quinta geração $(1,23 \mathrm{~kg})$, fato que está relacionado ao aumento da taxa metabólica em virtude do maior ímpeto em ganho de peso dos novilhos, o que pode ser ressaltado pela correlação entre o ganho médio diário de peso o peso absoluto do total de órgãos internos ( $\mathrm{r}=0,75 ; \mathrm{P}=0,0001)$. Para Kuss et al. ${ }^{1}$, bovinos destinados à produção de carne, como o caso da raça Charolês, selecionados para altas taxas de ganho de peso, apresentam maior consumo de alimento, sendo necessário aumento simultâneo dos órgãos responsáveis pelo metabolismo basal. De acordo com Perón et al. ${ }^{29}$, bovinos de origem europeia tendem a apresentar maior massa de órgãos internos em relação a animais zebuínos, informação ratificada por Véras et al. ${ }^{3}$. Conforme Jones et $\mathrm{al}^{30}$, bovinos oriundos do cruzamento de raças de grande porte apresentam maior peso absoluto dos órgãos internos em relação aos animais de pequeno porte. Smith \& Baldwin ${ }^{21}$ citam que coração, fígado e trato gastrintestinal estão entre os tecidos de maior atividade metabólica.

Para o total de gorduras depositadas pelos novilhos (Tabela 6), o efeito heterótico foi significativo na quinta $(2,99 \mathrm{~kg})$ e sexta $(3,41 \mathrm{~kg})$ gerações do cruzamento entre as raças Charolês e Nelore. De acordo com Pacheco et al. ${ }^{31}$, o acúmulo de tecido adiposo acarreta maior gasto energético (e de alimentos) para ser depositado, prejudicando a lucratividade do produtor. Esses autores verificaram que o total de gorduras internas apresentaram correlações de $-0,68$ e $-0,76$ com os rendimentos de carcaça quente e fria, ajustadas ao peso de corpo vazio, respectivamente.

Tabela 6 - Efeito heterótico e diferença entre novilhos cruzados e definidos para os conjuntos dos diferentes componentes não-integrantes a carcaça de novilhos de diferentes genótipos e gerações do cruzamento entre as raças Charolês e Nelore

\begin{tabular}{|c|c|c|c|c|c|c|c|c|c|c|}
\hline \multirow{3}{*}{ Grupo Genético } & \multicolumn{10}{|c|}{ Conjunto dos componentes } \\
\hline & \multicolumn{2}{|c|}{ Componentes Externos } & \multicolumn{2}{|c|}{ Trato Digestório } & \multicolumn{2}{|c|}{ Órgãos Internos } & \multicolumn{2}{|c|}{ Gorduras } & \multicolumn{2}{|c|}{ Sangue } \\
\hline & $\mathrm{Kg}$ & $\begin{array}{l}\text { \% Peso de } \\
\text { corpo vazio }\end{array}$ & $\mathrm{Kg}$ & $\begin{array}{l}\% \text { Peso de } \\
\text { corpo vazio }\end{array}$ & $\mathrm{Kg}$ & $\begin{array}{l}\% \text { Peso de } \\
\text { corpo vazio }\end{array}$ & $\mathrm{Kg}$ & $\begin{array}{l}\text { \% Peso de } \\
\text { corpo vazio }\end{array}$ & $\mathrm{kg}$ & $\begin{array}{l}\text { \% Peso de } \\
\text { corpo vazio }\end{array}$ \\
\hline Charolês & $51,6 \pm 1,51$ & $15,1 \pm 0,25 \mathrm{~b}$ & $18,5 \pm 0,79 a$ & $5,41 \pm 0,13 a$ & $13,4 \pm 0,49 a$ & $3,93 \pm 0,07$ & $19,0 \pm 1,02$ & $5,58 \pm 0,23$ & $17,3 \pm 0,98 \mathrm{a}$ & $5,06 \pm 0,25$ \\
\hline Nelore & $47,4 \pm 2,27$ & $16,1 \pm 0,38 \mathrm{a}$ & $13,9 \pm 1,19 b$ & $4,75 \pm 0,20 \mathrm{~b}$ & $10,8 \pm 0,73 b$ & $3,68 \pm 0,10$ & $16,5 \pm 1,53$ & $5,61 \pm 0,34$ & $12,3 \pm 1,48 b$ & $4,25 \pm 0,37$ \\
\hline Média Definidos & $49,5 \pm 1,36$ & $15,6 \pm 0,23$ & $16,2 \pm 0,72$ & $5,08 \pm 0,12$ & $12,1 \pm 0,44$ & $3,80 \pm 0,06$ & $17,7 \pm 0,92$ & $5,59 \pm 0,21$ & $14,8 \pm 0,88$ & $4,66 \pm 0,22$ \\
\hline $21 / 32 \mathrm{Ch} 11 / 32 \mathrm{Ne}$ & $53,8 \pm 1,37$ & $14,7 \pm 0,23$ & $19,9 \pm 0,72 \mathrm{a}$ & $5,46 \pm 0,12$ & $14,0 \pm 0,44$ & $3,84 \pm 0,06$ & $21,7 \pm 0,92$ & $5,98 \pm 0,21$ & $16,0 \pm 0,89$ & $4,40 \pm 0,22$ \\
\hline $21 / 32 \mathrm{Ne} 11 / 32 \mathrm{Ch}$ & $52,0 \pm 1,31$ & $15,2 \pm 0,22$ & $17,8 \pm 0,69 \mathrm{~b}$ & $5,19 \pm 0,11$ & $12,7 \pm 0,42$ & $3,70 \pm 0,06$ & $19,8 \pm 0,88$ & $5,72 \pm 0,20$ & $13,6 \pm 0,85$ & $3,96 \pm 0,21$ \\
\hline Média 5a Geração & $52,9 \pm 0,94$ & $15,0 \pm 0,16$ & $18,9 \pm 0,50$ & $5,33 \pm 0,08$ & $13,4 \pm 0,31$ & $3,77 \pm 0,04$ & $20,7 \pm 0,64$ & $5,85 \pm 0,14$ & $14,8 \pm 0,62$ & $4,18 \pm 0,15$ \\
\hline Efeito heterótico G5 & $3,45 \pm 1,66^{*}$ & $-0,61 \pm 0,27^{*}$ & $2,65 \pm 0,87^{*}$ & $0,24 \pm 0,15$ & $1,23 \pm 0,54^{*}$ & $-0,03 \pm 0,07$ & $2,99 \pm 1,12^{*}$ & $0,26 \pm 0,25$ & $-0,02 \pm 1,08$ & $-0,47 \pm 0,27$ \\
\hline $43 / 64 \mathrm{Ch} 21 / 64 \mathrm{Ne}$ & $50,4 \pm 1,71$ & $14,4 \pm 0,28 b$ & $18,9 \pm 0,90$ & $5,38 \pm 0,15$ & $13,5 \pm 0,56$ & $3,84 \pm 0,07$ & $21,7 \pm 1,16$ & $6,17 \pm 0,26$ & $15,3 \pm 1,11$ & $4,33 \pm 0,28$ \\
\hline $43 / 64 \mathrm{Ne} 21 / 64 \mathrm{Ch}$ & $54,8 \pm 2,27$ & $15,6 \pm 0,38 \mathrm{a}$ & $17,9 \pm 1,07$ & $5,12 \pm 0,18$ & $13,0 \pm 0,66$ & $3,73 \pm 0,09$ & $20,5 \pm 1,37$ & $5,91 \pm 0,31$ & $12,9 \pm 1,32$ & $3,64 \pm 0,33$ \\
\hline Média 6a Geração & $52,7 \pm 1,42$ & $15,0 \pm 0,23$ & $18,4 \pm 0,70$ & $5,25 \pm 0,12$ & $13,3 \pm 0,43$ & $3,79 \pm 0,06$ & $21,2 \pm 0,89$ & $6,05 \pm 0,20$ & $14,1 \pm 3,88$ & $3,98 \pm 0,22$ \\
\hline Efeito heterótico G6 & $3,18 \pm 1,97$ & $-0,61 \pm 0,31^{*}$ & $2,18 \pm 1,00^{*}$ & $0,17 \pm 0,17$ & $1,13 \pm 0,62$ & $-0,02 \pm 0,08$ & $3,41 \pm 1,28^{*}$ & $0,45 \pm 0,29$ & $-0,73 \pm 1,24$ & $-0,67 \pm 0,31^{*}$ \\
\hline \multicolumn{11}{|l|}{ Diferenças } \\
\hline Cruzados e Ch & $1,20 \pm 1,73$ & $-0,08 \pm 0,29$ & $0,15 \pm 0,90$ & $-0,12 \pm 0,15$ & $-0,13 \pm 0,56$ & $-0,15 \pm 0,07$ & $1,91 \pm 1,16$ & $0,37 \pm 0,26$ & $-2,87 \pm 1,12^{*}$ & $-0,98 \pm 0,28^{*}$ \\
\hline Cruzados e Ne & $5,42 \pm 2,42^{*}$ & $-1,15 \pm 0,40^{*}$ & $4,68 \pm 1,27^{*}$ & $0,53 \pm 0,21^{*}$ & $2,49 \pm 0,78 *$ & $0,09 \pm 0,10$ & $4,48 \pm 1,62^{*}$ & $0,34 \pm 0,37$ & $2,11 \pm 1,57$ & $-0,16 \pm 0,39$ \\
\hline
\end{tabular}


Tabela 7 - Correlações entre pesos e rendimentos de carcaça e ganho médio diário com partes não-integrantes a carcaça

\begin{tabular}{|c|c|c|c|c|c|c|c|c|c|c|c|c|c|c|c|c|c|c|c|c|}
\hline \multirow{3}{*}{\multicolumn{2}{|c|}{ Variáveis }} & & \multicolumn{3}{|c|}{ Pesos, kg } & \multicolumn{4}{|c|}{ Rendimentos de carcaça } & \multirow{3}{*}{$\begin{array}{l}\text { Ganho } \\
\text { médio } \\
\text { diário }\end{array}$} & \multirow{2}{*}{\multicolumn{2}{|c|}{$\begin{array}{l}\text { Componentes } \\
\text { Externos }\end{array}$}} & \multirow{2}{*}{\multicolumn{2}{|c|}{$\begin{array}{c}\text { Trato } \\
\text { Digestório }\end{array}$}} & \multirow{2}{*}{\multicolumn{2}{|c|}{$\begin{array}{c}\text { Órgãos } \\
\text { Intemos }\end{array}$}} & \multirow{2}{*}{\multicolumn{2}{|c|}{ Gorduras }} & \multirow{2}{*}{\multicolumn{2}{|c|}{ Sangue }} \\
\hline & & & \multirow{2}{*}{$\begin{array}{l}\text { Corpo } \\
\text { vazio }\end{array}$} & \multicolumn{2}{|c|}{ Carcaça } & \multicolumn{2}{|c|}{$\%$ Peso de abate } & \multicolumn{2}{|c|}{$\% \mathrm{PCV}$} & & & & & & & & & & & \\
\hline & & & & Quente & Fria & Quente & Fria & Quente & Fria & & $\mathrm{kg}$ & $\% \mathrm{PCV}$ & $\mathbf{k g}$ & $\%$ PCV & $\mathbf{k g}$ & $\%$ PCV & $\mathrm{Kg}$ & $\%$ PCV & $\mathrm{Kg}$ & $\%$ PCV \\
\hline \multirow{8}{*}{ 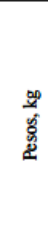 } & \multirow{2}{*}{ Abate } & r & 0,99 & 0,98 & 0,98 & 0,08 & 0,09 & 0,25 & 0,25 & 0,80 & 0,85 & $-0,54$ & 0,85 & 0,26 & 0,88 & 0,06 & 0,69 & 0,05 & 0,48 & 0,01 \\
\hline & & $P$ & 0,0001 & 0,0001 & 0,0001 & 0,5866 & 0,5541 & 0,0846 & 0,0866 & 0,0001 & 0,0001 & 0,0001 & 0,0001 & 0,0727 & 0,0001 & 0,7413 & 0,0008 & 0,7134 & 0,0005 & 0,9960 \\
\hline & \multirow[b]{2}{*}{ Corpo vazio } & I & & 0,98 & 0,98 & 0,17 & 0,17 & 0,25 & 0,23 & 0,78 & 0,85 & $-0,57$ & 0,84 & 0,24 & 0,89 & 0,06 & 0,68 & 0,03 & 0,53 & 0,06 \\
\hline & & $P$ & & 0,0001 & 0,0001 & 0,2498 & 0,2506 & 0,0821 & 0,1021 & 0,0001 & 0,0001 & 0,0001 & 0,0001 & 0,1002 & 0,0001 & 06719 & 0,0001 & 0,8418 & 0,0001 & 0,6932 \\
\hline & \multirow{2}{*}{ Carcaça quente } & I & & & 0,99 & 0,28 & 0,28 & 0,39 & 0,37 & 0,77 & 0,81 & $-0,60$ & 0,81 & 0,19 & 0,86 & 0,01 & 0,62 & $-0,03$ & 0,45 & $-0,03$ \\
\hline & & $P$ & & & 0,0001 & 0,0496 & 0,0511 & 0,0050 & 0,0089 & 0,0001 & 0,0001 & 0,0001 & 0,0001 & 0,1912 & 0,0001 & 0,9264 & 0,0001 & 0,8074 & 0,0001 & 0,8296 \\
\hline & \multirow{2}{*}{ Carcaça fria } & I & & & & 0,27 & 0,28 & 0,39 & 0,38 & 0,78 & 0,82 & $-0,59$ & 0,81 & 0,19 & 0,86 & $-0,02$ & 0,63 & $-0,02$ & 0,45 & $-0,03$ \\
\hline & & $P$ & & & & 0,0643 & 0,0496 & 0,0059 & 0,0064 & 0,0001 & 0,0001 & 0,0001 & 0,0001 & 0,1802 & 0,0001 & 0,8673 & 0,0001 & 0,8673 & 0,0001 & 0,8119 \\
\hline \multirow{8}{*}{ 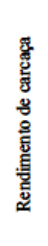 } & Quente, \% peso & r & & & & & 0,95 & 0,76 & 0,65 & $-0,006$ & $-0,02$ & $-0,34$ & $-0,04$ & $-0,30$ & 0,04 & $-0,22$ & $-0,06$ & $-0,42$ & $-0,06$ & $-0,17$ \\
\hline & abate & $\mathbf{P}$ & & & & & 0,0001 & 0,0001 & 0,0001 & 0,9636 & 0,8656 & 0,0188 & 0,7939 & 0,0390 & 0,7626 & 0,1266 & 0,6871 & 0,0029 & 0,6931 & 0,2333 \\
\hline & \multirow{2}{*}{ Fria, \% peso abate } & I & & & & & & 0,75 & 0,75 & 0,0002 & $-0,02$ & $-0,33$ & $-0,03$ & $-0,27$ & 0,03 & $-0,24$ & $-0,17$ & $-0,38$ & $-0,08$ & $-0,20$ \\
\hline & & $P$ & & & & & & 0,0001 & 0,0001 & 0,9999 & 0,8694 & 0,0210 & 0,8277 & 0,0559 & 0,8272 & 0,0920 & 0,2437 & 0,0076 & 0,5906 & 0,1594 \\
\hline & \multirow{2}{*}{ Quente, \% PCV } & I & & & & & & & 0,93 & 0,20 & 0,09 & $-0,31$ & 0,06 & $-0,21$ & 0,09 & $-0,28$ & $-0,11$ & $-0,40$ & $-0,35$ & $-0,57$ \\
\hline & & $P$ & & & & & & & 0,0001 & 0,1708 & 0,5278 & 0,0327 & 0,6657 & 0,1416 & 0,5259 & 0,0492 & 0,4225 & 0,0045 & 0,0145 & 0,0001 \\
\hline & \multirow{2}{*}{ Fria, \% PCV } & r & & & & & & & & 0,20 & 0,09 & $-0,28$ & 0,07 & $-0,17$ & 0,07 & $-0,29$ & $-0,07$ & $-0,32$ & $-0,36$ & $-0,59$ \\
\hline & & $P$ & & & & & & & & 0,1606 & 0,5335 & 0,0537 & 0,6315 & 0,2416 & 0,6130 & 0,0427 & 0,6258 & 0,0243 & 0,0106 & 0,0001 \\
\hline \multicolumn{2}{|c|}{ Ganho médio } & $\mathbf{r}$ & & & & & & & & & 0,67 & $-0,43$ & 0,71 & 0,28 & 0,75 & 0,16 & 0,52 & 0,01 & 0,33 & $-0,04$ \\
\hline \multicolumn{2}{|c|}{ Diário, kg } & $P$ & & & & & & & & & 0,0001 & 0,0021 & 0,0001 & 0,0525 & 0,0001 & 0,2647 & 0,0001 & 0,9598 & 0,0185 & 0,7599 \\
\hline Comp & onetes & r & & & & & & & & & & $-0,06$ & 0,73 & 0,22 & 0,74 & $-0,01$ & 0,45 & $-0,14$ & 0,37 & $-0,05$ \\
\hline Exten & los, $\mathrm{kg}$ & $P$ & & & & & & & & & & 0,6840 & 0,0001 & 0,1412 & 0,0001 & 0,9742 & 0,0015 & 0,3275 & 0,0094 & 0,7425 \\
\hline Trato & & I & & & & & & & & & & & & 0,71 & 0,90 & $-0,37$ & 0,51 & $-0,05$ & 0,38 & $-0,03$ \\
\hline Diges & ónio, $\mathbf{k g}$ & $P$ & & & & & & & & & & & & 0,0001 & 0,0001 & 0,0088 & 0,0002 & 0,7300 & 0,0080 & 0,8024 \\
\hline Órgão & & I & & & & & & & & & & & & & & 0,50 & 0,58 & 0,01 & 0,47 & 0,05 \\
\hline Intern & $\mathrm{ss}, \mathbf{k g}$ & $P$ & & & & & & & & & & & & & & 0,0003 & 0,0001 & 0,9900 & 0,0006 & 0,7130 \\
\hline & & I & & & & & & & & & & & & & & & & 0,75 & 0,42 & 0,10 \\
\hline Gordu & ras, kg & $\mathbf{P}$ & & & & & & & & & & & & & & & & 0,0001 & 0,0031 & 0,4777 \\
\hline
\end{tabular}

Solis et al..$^{32}$ observaram menor exigência de mantença para vacas da raça Brahman em comparação a vacas taurinas e atribuíram o fato, em parte, à menor deposição de gordura interna e à menor atividade metabólica dos órgãos internos desses animais. A quantidade de tecido adiposo depositado no corpo dos animais condiciona sua eficiência alimentar, pois este tecido, em comparação ao tecido muscular, requer maior quantidade de nutrientes para sua deposição ${ }^{8}$. Cattelam et al. ${ }^{15}$ observaram menor ganho médio diário de peso em bovinos castrados em comparação a animais nãocastrados, fato que os autores associaram, em parte, à maior deposição de gordura nos animais orquiectomizados.

A quantidade de sangue presentou efeito heterótico apenas quando ajustado ao peso de corpo vazio na sexta geração, com valor de $-0,65 \%$. O peso do sangue, em $\mathrm{kg}$, esteve positivamente correlacionado ao ganho médio diário de peso $(\mathrm{r}=$ 0,33; $\mathrm{P}=0,0185$ ), assim como com o conjunto dos componentes externos $(\mathrm{r}=0,37 ; \mathrm{P}=0,0094)$, trato digestório $(\mathrm{r}=0,38 ; \mathrm{P}=0,0080)$; órgãos internos $(\mathrm{r}=$ $0,47 ; \mathrm{P}=0,0006)$ e gorduras $(\mathrm{r}=0,42 ; \mathrm{P}=0,0031)$, conforme exposto na Tabela 7. De acordo com Kuss et al. ${ }^{1}$, com o incremento na deposição de tecidos, é necessário maior aporte sanguíneo para a condução dos nutrientes. $\mathrm{O}$ aumento no volume de sangue acompanha o incremento dos órgãos vitais e do trato digestório, o que seria necessário para acompanhar variações na taxa metabólica dos animais ${ }^{33}$.

$\mathrm{Na}$ avaliação da diferença entre cruzados e definidos, observa-se que os mestiços foram positivamente superiores ao Nelore para todos os conjuntos analisados (Tabela 6), o que demonstra o ímpeto de crescimento que a participação da raça Charolês promove nas partes não-integrantes à carcaça de novilhos.

\section{CONCLUSÃO}

Novilhos provenientes do cruzamento entre as raças Charolês e Nelore apresentam maior desenvolvimento de rúmen-retículo e intestinos em relação a animais definidos dessas raças, influenciados, sobretudo, pelo genótipo taurino.

Novilhos cruzados apresentam maiores pesos dos diferentes conjuntos dos componentes externos à carcaça em relação a animais definidos das raças Charolês e Nelore.

A participação da raça Charolês no cruzamento com a raça Nelore aumenta o peso dos órgãos internos enquanto a participação do genótipo zebuíno eleva os rendimentos de carcaça e a participação do couro em relação ao peso de corpo vazio.

\section{REFERÊNCIAS}

1. Kuss F, Restle J, Brondani IL, Pacheco PS, Silveira 
MF, Pazdiora RD, Cezimbra IM. Órgãos vitais e trato gastrintestinal de vacas de descarte mestiças Charolês $\mathrm{x}$ Nelore abatidas com distintos pesos. Revista Brasileira de Zootecnia. 2007a. 36 (2): 421-429.

2. Missio RL, Brondani IL, Restle J, Silva JHS, Silveira MF, Silva VS. Partes não-integrantes da carcaça de tourinhos alimentados com diferentes níveis de concentrado na dieta. Revista Brasileira de Zootecnia. 2010. 38 (5): 906-915.

3. Véras ASC, Valadares Filho SC, Silva JFC, Paulino MF, Cecon PR, Valadares RFD, Ferreira MA, Fontes CMS. Efeito do nível de concentrado sobre o peso dos órgãos internos e do conteúdo do trato gastrintestinal do bovinos Nelore não-castrados [Effect of concentrate level on the internal organs weight and gastrintestinal content of nellore bulls]. Revista Brasileira de Zootecnia [Internet]. 2001. [cited 2014 Jan 25]; 30 (3): 1120-1126 (Suplemento). Avaliable from: http://www.revista.sbz.org.br/artigo/index.php?artigo=282 $\underline{0}$

4. Melo WS, Véras ASC, Ferreira MA, Dutra Júnior WM, Andrade DKB, Santos GRA Cortes nobres, componentes do peso vivo e órgãos viscerais de bovinos mestiços de origem leiteira em condições de pastejo, restrito e "ad libtum" [Noble cuts, live weight components and visceral organs of dairy crossbreds bulls in grazing, restricted or ad libitum]. Revista Brasileira de Ciências Agrárias [Internet]. [cited 2014 Jan 25]; 2 (1): 90-97. Avaliable from:

http://agraria.pro.br/sistema/index.php?journal=agraria\&p age $=$ article \&op $=$ path $\% 5 \mathrm{~B} \% 5 \mathrm{D}=96 \&$ path $\% 5 \mathrm{~B} \% 5 \mathrm{D}=75$

5. Cattelam J, Silevira MF, Sachet RH, Freitas LS, Pacheco RF, Moura RM, Alves Filho DC, Brondani IL. Órgãos internos e trato digestório de novilhos superprecoces não castrados ou castrados de dois grupos genéticos. Arquivo Brasileiro de Medicina Veterinária e Zootecnia. 2011a. 63 (5): 1167-1174.

6. Jorge AM, Fontes CAA. Desenvolvimento relativo das partes do corpo de zebuínos de quatro raças. Ciência Rural. 2001. 31 (5): 857-861.

7. Pacheco PS, Restle J, Silva JHS, Arboitte MZ; Alves Filho DC, Freitas AK, Rosa JRP, Pádua JT. Características das partes do corpo não-integrantes da carcaça de novilhos jovens e superjovens de diferentes grupos genéticos. Revista Brasileira de Zootecnia. 2005. 34 (5): 1678-1690.

8. Kuss F, Restle J, Brondani IL, Pascoal LL, Menezes, LFG, Leite DT, Santos MF. Componentes externos do corpo e gordura de descarte em vacas mestiças Charolês $\mathrm{x}$ Nelore abatidas com diferentes pesos. Revista Brasileira de Zootecnia. 2007b. 36 (4): 865-873.

9. Menezes LFG, Restle J, Brondani IL, Kuss F, Alves Filho DC, Silveira MF, Leite DT. Órgãos internos e trato gastrintestinal de novilhos de gerações avançadas do cruzamento rotativo entre as raças Charolês e Nelore, terminados em confinamento. Revista Brasileira de
Zootecnia. 2007. 36 (1): 120-129.

10. Menezes LFG, Restle J, Brondani IL, Alves Filho DC, Pascoal LL, Silva JHS. Distribuição das gorduras internas e de descarte e componentes externos do corpo de novilhos de gerações avançadas do cruzamento rotativo entre as raças Charolês e Nelore. Revista Brasileira de Zootecnia. 2009. 38 (2): 338-345.

11. Jorge AM, Fontes CAA, Paulino MF, Gomes Júnior P. Tamanho relativo dos órgãos internos de zebuínos sob alimentação restrita e "ad libitum" [Relative size of internal organs of zebu cattle under restricted and full fed feeding]. Revista da Brasileira de Zootecnia [Internet]. 1999. [cited 2014 Jan 31]. 28 (2): 374-380. Avaliable from:

http://www.revista.sbz.org.br/artigo/index.php?artigo=199 $\underline{2}$

12. Streck EV, Kämpf N, Dalmolin RSD, Klamt E, Nascimento PC, Schneider P. Solos do Rio Grande do Sul. $2^{\circ}$ ed. rev. e ampl. Porto Alegre: EMATER/RS-ASCAR, 2008. 222p.

13. Lowan BG, Scott N, Somerville S. Condition scoring beef cattle. Edinburgh: East of Scotland College of Agriculture. 1973. 8p. (Bulletin 6)

14. Menezes LFG, Restle J, Brondani IL, Alves Filho DC, Kuss F, Silveira MF, Amaral GA. Características da carcaça de novilhos de gerações avançadas do cruzamento alternado entre as raças Charolês e Nelore, terminados em confinamento. Revista Brasileia de Zootecnia. 2005. 34 (3): 934-945.

15. Cattelam J, Freitas LS, Brondani IL, Silva JHS, Arboitte MZ, Weise MS. Características dos componentes externos e das gorduras descartadas de novilhos superprecoces não-castrados ou castrados de dois genótipos, terminados em confinamento. Revista Brasileira de Zootecnia. 2011b. 40 (8): 1774-1780.

16. Cattelan J, Menezes LFG, Ferreira JJ, Restle J, Alves Filho DC, Brondani IL. Gorduras de descarte e componentes externos do corpo de novilhos e vacas de descarte de diferentes grupos genéticos. Ciência Rural. 2010. 40 (12): 2541-2548.

17. Restle J, Vaz FN, Quadros ARB, Müller L. Características de carcaça e da carne de novilhos de diferentes genótipos de Hereford $\mathrm{x}$ Nelore [Carcass and meat characteristics from steers of different of Hereford $\mathrm{x}$ Nellore genotypes]. Revista Brasileira de Zootecnia [Internet]. [cited 2014 Jan 25]; 1999. 28 (6): 1245-1251. http://www.revista.sbz.org.br/artigo/index.php?artigo=245 $\underline{7}$

18. Silva Sobrinho AC, Gastaldi KA, Garcia CA, Machado MRF. Diferentes dietas e pesos ao abate na produção de órgãos de cordeiros [Different diets and slaughter weights affecting organ production of lambs]. Revista Brasileira de Zootecnia [Internet]. [cited 2014 Jan 25]; 2003. 32 (6): 1792-1799. (Suplemento). Avaliable form:

http://www.revista.sbz.org.br/artigo/index.php?artigo=365 


\section{$\underline{0}$}

19. Menezes LFG, Restle J, Kuss F, Brondani IL, Alves Filho DC, Catellam J, Osmari MP. Medidas corporais de novilhos de gerações avançadas do cruzamento rotativo entre as raças Charolês e Nelore, terminados em confinamento [Body measurements of feedlot finished steers from advanced generations of rotational crossbreeding between Charolais and Nellore breeds]. Ciência Rural [Internet]. 2008. [cited 2014 Jan 31]. 38 (3): 771-777. Avaliable http://www.scielo.br/pdf/cr/v38n3/a28v38n3.pdf

20. Signoretti RD, Silva JFC, Valadadres Filho SC, Pereira JC, Araújo GGL, Cecon PR, Queiroz AC, Muniz EB. Crescimento, conversão alimentar e rendimento de carcaça de bezerros da raça holandesa alimentados contendo diferentes níveis de volumoso [Growth, feed:gain ratio and carcass yield of holstein calves fed diets with different levels of forage]. Revista Brasileira de Zootecnia [Internet]. [cited 2014 Jan 25]; 1999. 28 (1): 185-194. Avaliable from: http://www.revista.sbz.org.br/artigo/index.php?artigo $=230$ $\underline{0}$

21. Smith NE, Baldwin RL. Effects of breed, pregnancy and lactation on weight of organs and tissues in dairy cattle. Journal of Dairy Science [Internet]. 1974. [cited 2014 Jan 31]. 57 (9): 1055-1060. Avaliable from: http://download.journals.elsevierhealth.com/pdfs/journals/ 0022-0302/PIIS0022030274850083.pdf

22. Ferrell CL, Garret WN, Hinman N. Estimation of body composition in pregnant and non pregnant heifers. Journal of Animal Science [Internet]. 1976. [cited 2014 Jan 31] 42 (5): 1158-1166. Avaliable from: http://www.journalofanimalscience.org/content/42/5/1158. full.pdf+html?sid=a25332b9-9889-4d61-bc189f503c42229d

23. Menezes LFG, Cattelam J, Ferreira JJ, Restle J, Brondani IL, Alves Filho DC. Órgãos internos e trato digestório de novilhos e vacas de descarte de diferentes grupos genéticos. Ciência Animal Brasileira. 2013.14 (4): $418-425$.

24. Owens FN, Gill DR, Secrist DS, Coleman SW. Review of some aspects of growth and development of feedlot Journal of Animal Science [Internet]. 1995. [cited 2014 Jan 31], 73 (10): 3152-3172. Avaliable from: http://www.journalofanimalscience.org/content/73/10/315 2.full.pdf+html?sid=98799f0a-7bab-4062-98b1-88 $\underline{418486 \mathrm{ae} 2 \mathrm{av}}$

25. Costa DPB, Rodrigues VC, Silva JCG, Mourão RC, Cabral Neto O, Costa QPB. Avaliação das vísceras de novilhos Nelore e F1 Nelore x Sindi aos 36 e 48 meses de idade [Viscera evaluation of Nellore and f1 Nellore $\mathrm{x}$ Sind steers with 36 and 48 months old age]. Ciência Animal Brasileira [Internet].2007. [cited 2014 Jan 25]; 8 (1): 1723. Avaliable from: http://www.revistas.ufg.br/index.php/vet/article/view/115 $\underline{4 / 1244}$

26. Gesualdi Júnior A, Veloso CM, Paulino MF,
Valadares Filho SC, Gesualdi ACLS, Cecon PR. Níveis de concentrado na dieta de bovinos F1 Limousin x Nelore: peso dos órgãos internos e trato digestório [Concentrate levels in diets of Limousin x Nelore bulls: internal organs and digestive tract weight]. Revista Brasileira de Zootecnia [Internet]. 2001. [cited 2014 Jan 31]; 30 (6): 1866-1871. Avaliable from: http://www.revista.sbz.org.br/artigo/index.php?artigo=317 $\underline{1}$

27. Di Marco ON. Crecimiento de vacunos para carne. 1.ed. Mar del Plata: Balcarce; 1998. 246p.

28. Ferrell CL, Jenkins TG. Body composition and energy utilization by steers of diverse genotypes fed a highconcentrate diet during the finishing period: II. Angus, Boran, Brahman, Hereford, and Tuli sires. Journal of Animal Science [Internet]. 1998. [cited 2014 Jan 31]; 76 (2): 647-657. Avaliable from: http://www.journalofanimalscience.org/content/76/2/647.f ull.pdf+html

29. Peron AJ, Fontes CAA, Lana RP, Silva DJ, Queiroz AC, Paulino M. Tamanho de órgãos internos e distribuição da gordura corporal em novilhos de cinco grupos genéticos, submetidos a alimentação restrita e $a d$ libitum. [Effect of nutritional level and breed group on size of internal organs and body fat distribuition of steers]. Revista Brasileira de Zootecnia [Internet]. [cited 2014 Jan 25]; 1993. 22 (5): 813-819. Avaliable from: http://www.revista.sbz.org.br/artigo/visualizar.php?artigo $=610$

30. Jones SMD, Rompala RE, Jeremiah LE. Growth and composition of the empty body in steers of different maturity types fed concentrate or forage diets. Journal of Animal Science [Internet]. 1985. [cited 2014 Jan 31], 60 (2): 427-433. Avaliable from: http://www.journalofanimalscience.org/content/60/2/427.f ull.pdf+html ?sid=ebf4306f-15e5-4524-bd94$\underline{01 \mathrm{a} 234 \mathrm{~d} 4 \mathrm{dc} 6 \mathrm{e}}$

31. Pacheco PS, Restle J, Silva JHS, Freitas AK, Arboitte MZ, Pádua JT. Relação entre os componentes do corpo vazio e rendimentos de carcaça de novilhos de corte. Ciência Animal Brasileira, v.7, n.2, p.107-113, 2006. [Relationship among empty body components and dressing percentages of carcass of beef steers]. Ciência Animal Brasileira [Internet]. 2006. [cited 2014 Jan 25]; 8 (1): 17-23. Avaliable from: http://www.revistas.ufg.br/index.php/vet/article/view/404/ $\underline{0}$

32. Solis JC, Byers FM, Schelling GT, Long CR, Greene LW. Maintenance requirements and energrtic efficiency of cows of different breed types. Journal of Animal Science [Internet]. 1988. [cited 2014 Jan 31]. 66 (3): 764-773. Avaliable from: http://www.journalofanimalscience.org/content/66/3/764.f ull.pdf+html? sid=fb0c1da3-f382-4d0c-963c$499 \mathrm{feb} 4 \mathrm{~b} 5 \mathrm{e} 8 \mathrm{~d}$

33. Ribeiro TR, Pereira JC, Leão MI, Oliveira MVM, Queiroz AC, Cecon PR, Melo RCA. Tamanho dos órgãos 
e vísceras de bezerros holandeses, para a produção de vitelos recebendo dietas com diferentes níveis de concentrado [Size of internal organs and viscera of holstein veal calves fed diets containing various levels of concentrate]. Revista Brasileira de Zootecnia [Internet].
2001. [cited 2014 Jan 25]; 30 (6): 2163-2168.

(Suplemento). Avaliable from: http://www.revista.sbz.org.br/artigo/index.php?artigo=303 $\underline{6}$

Protocolado em: 29 jan. 2014 Aceito em: 28 abr. 2014 